\title{
BMJ Global Health Duty of care and health worker protections in the age of Ebola: lessons from Médecins Sans Frontières
}

\author{
Melissa McDiarmid, ${ }^{\oplus 1}$ Rosa Crestani ${ }^{2}$
}

To cite: McDiarmid M, Crestani R. Duty of care and health worker protections in the age of Ebola: lessons from Médecins Sans Frontières. BMJ Global Health 2019;4:e001593. doi:10.1136/ bmjgh-2019-001593

Handling editor Seye Abimbola

Received 29 March 2019 Revised 15 August 2019 Accepted 18 August 2019

Check for updates

(C) Author(s) (or their employer(s)) 2019. Re-use permitted under CC BY-NC. No commercial re-use. See rights and permissions. Published by BMJ.

${ }^{1}$ Medicine, University of Maryland School of Medicine, Baltimore, Maryland, USA ${ }^{2}$ Médecins Sans Frontières, Brussels, Belgium

Correspondence to Dr Melissa McDiarmid; mmcdiarm@som.umaryland. edu

\section{INTRODUCTION}

Protecting health workers from preventable illness, disability and death must become a fundamental first step in building resilient health systems capable of planning for and effectively responding to public health emergencies while maintaining core services. ${ }^{12}$ The health sector is already known as a 'highhazard' employment zone, even when workers provide routine clinical care under circumstances clearly safer than an emergency response. ${ }^{3}$ Beyond the anticipated infectious agents such as tuberculosis and hepatitis that a worker might encounter, other hazard categories include chemical, physical and psychological risks which threaten worker health and safety. ${ }^{4}$

The sector's poor workforce illness and injury rates reflect these hazards, even in well-resourced settings. In the UK, for example, illness and injury rates are about $30 \%$ higher than the all industry average. ${ }^{5}$ These hazards not only endanger the personal safety of skilled health staff, but cripple health systems already burdened by workforce shortages.

In the special case of public health emergencies, unique threats arising from the complexity of urgent care delivery add to the heightened health worker occupational risk. This was especially evident in the Ebola context, where significant health worker infections and deaths occurred during the initial emergence and in subsequent early hospital-based outbreaks. ${ }^{6}$

Recent review of the largely WHO-led Ebola response of 2014 to 2015 examined health worker infections and deaths. Though exact numbers were never finalised, two-thirds of the 815 known and presumed health workers infected were reported to have died of the disease. The estimated cumulative Ebola Virus Disease incidence rate for health workers was reported to range from about

\section{Summary box}

Health workers were differentially infected during the 2014 to 2016 Ebola outbreak with an incidence rate of 30 to $44 / 1000$ depending on their job duties, compared to the wider population's rate of $1.4 / 1000$ according to the WHO.

- Médecins Sans Frontières (MSF) health workers had a much lower incidence rate of 4.3/1000, explained as the result of MSF's 'duty of care' toward staff safety.

- Duty of care is defined as an obligation to conform to certain standards of conduct for the protection of others against an unreasonable risk of harm.

- The duty of care was operationalised through four actions: performing risk assessments prior to deployment, organising work and work practices to minimise exposure, providing extensive risk communication and training of staff and providing medical follow-up for staff exposures.

- Adopting and consistently enforcing these broader duty of care safety policies in deployed teams augments and fortifies standard infection prevention practices, creating a more protective, comprehensive safety programme.

- Prioritising staff safety by taking such actions will help avoid the catastrophic loss of the health work force and assist in building resilient health systems.

30 to 44 per 1000 persons depending on job title, compared with the non-health worker rate of 1.4 per $1000 .{ }^{6}$ Compare this to the incidence rate of Médecins Sans Frontières (MSF) health workers, at about 4.3 per 1000 based on 28 infections among about 6500 responders. ${ }^{7}$

\section{MSF AND THE DUTY OF CARE}

Compared with other responding teams, MSF-deployed staff had significant experience in Ebola response and safety practices leading into 2014. Another specific difference, considering their lower staff infection rate, may be the agency's 'duty of care'. The 
concept of duty of care has roots in both ethics and the law and is generally defined as an obligation to conform to certain standards of conduct for the protection of others against an unreasonable risk of harm. ${ }^{8}$

The duty of care principle appears in professional codes of ethics for health workers to provide care for their patients, including obligations to populations during pandemics. ${ }^{9}$ After the severe acute respiratory syndrome epidemic and the notable loss of life among health workers, several authors raised the ethical need to consider the added risk workers assumed. They suggested that employers have a reciprocal obligation to their employees, which in some settings has become legally binding, to provide the needed training, organisation and protective equipment to make hazardous work as safe as possible. ${ }^{1011}$

Given their mission to respond to humanitarian emergencies, MSF is well aware of the out-sized safety and security risks that threaten health workers. Thus, duty of care as a policy, having evolved over time, was formalised in 2004. The policy committed the agency to operate under the obligation to protect its staff. ${ }^{12}$ As was observed during the Ebola outbreak, an imbalance in this reciprocity endured more broadly, where employers in both limited income and well-resourced countries failed to take commensurate protective actions against the risks workers were expected to shoulder.

The duty of care commitment is operationalised for all MSF missions in safety policies and practices, and is achieved through four actions:

1. Performing detailed analyses of health risks related to the job proposed.

2. Implementing all necessary preventive measures and actions to control risks including the design of safety and emergency procedures.

3. Informing workers of the remaining risks.

4. Providing follow-up for any illness or work-related injury.

\section{ANALYSES OF HEALTH RISKS RELATED TO THE JOB PROPOSED}

Months before the WHO declared the Ebola outbreak an international public health emergency in August 2014, MSF teams were already deployed to multiple sites in the affected West Africa region, providing patient care, contact tracing, community outreach and logistical support to the Ebola response. At the height of the agency's involvement, MSF had 14 different Ebola treatment projects across Guinea, Liberia and Sierra Leone, ultimately caring for about one-third of the total patients affected by the crisis. ${ }^{7}$

Prior to undertaking any of these new missions, experienced MSF staff conduct a health risk analysis (Action 1). Using a checklist to assess context, political background, health risks and population beliefs and behaviours, a general profile is determined for any new mission being considered. For Ebola missions, the availability of protective clothing, the circuit or layout of the treatment building and the training level of the staff is assessed. The overall risk is graded with a specific tool to determine if the risk is acceptable to undertake. If the mission is undertaken, monthly biosafety expert visitors from headquarters augment baseline safety assessments by performing monthly monitoring, again using checklists and a colour scale (green, yellow, red) for each performance element. This is shared with the local staff at the site level to encourage improvement over time. The health focal point also addresses ongoing health worker risk management and the 'wash' supervisor (water, sanitation and hygiene) reviews and provides feedback for the wash staff (staff who perform decontamination, laundry and burial duties).

\section{IMPLEMENTING PREVENTIVE MEASURES AND ACTIONS}

Health-related preventive actions (Action 2) include providing worker training to minimise infection risk. Pre-deployment, worker health status and vaccine documentation are validated and malaria prophylaxis is provided. The briefings and training for prospective international Ebola staff emphasise specific sanitation and infection prevention and control (IPC) work practices, which limit exposure to infectious body fluids or objects. This includes requiring strict adherence to the "no touch' policy of any other person, except when wearing proper personal protective equipment (PPE). Training to wear and safely remove PPE ensembles in hypothetical scenarios is also practiced and reinforced on site, as is safe duration times in treatment units to prevent heat stress. National staff follow a similar training process locally.

Both national and international MSF staff are required to observe health guidelines and IPC practices throughout the mission. ${ }^{1314}$ Logistical and medical coordinators ensure compliance on site by observing daily work performance, re-training staff on an ongoing basis and ensuring the availability of needed PPE. Human resource measures also encourage a positive safety climate through scheduled rest and days off, and by use of clear job profiles.

\section{WORKER RISK COMMUNICATION}

Risk analyses, including residual risk and safety policies, are extensively communicated through written documents and face-to-face briefings (Action 3). The special safety aspects of an Ebola mission, including modes of Ebola transmission, lack of efficient treatment and high risk of mortality are clearly communicated to staff in a safety policy. ${ }^{15}$ Prospective staff are informed of the right to withdraw from work if they do not feel safe. In some high-risk situations, a written consent is requested of the staff member to ensure their understanding of the remaining risk.

\section{PROVIDING FOLLOW-UP FOR ANY ILLNESS OR WORK-RELATED} INJURY

Staff illness, including suspected Ebola cases, are managed by the team-based health focal point (Action 4). Each site 
has the capacity to isolate and treat potentially infected staff. Standard operating procedures are detailed in policy documents. ${ }^{15}$ MSF Operational Centre's clinical expertise is also sought. Referral for treatment locally, nationally and internationally is based on availability but is preferentially provided in a special treatment facility for responder staff. Closely monitored medical and psychosocial follow-up is provided by MSF staff present on all Ebola mission teams, and at the capital and Operational Centre level if evacuation is required. After the mission, debriefing of staff occurs at both the country and headquarters level.

\section{LESSONS FROM THE MSF EBOLA EXPERIENCE}

It is difficult to make direct comparisons between the MSF-deployed teams and those organised by the WHO, though some broad observations are evident. Both WHO and partners, as well as MSF, deployed many diverse response teams composed of international and national staff. MSF also had comprehensive, agency-wide safety policies in place for health workers that went beyond IPC.

WHO-convened teams were guided primarily by IPC documents, ${ }^{16}$ though by the time these were available in August 2014, more than 400 health workers had already been infected. Prior to this, existing IPC guidance for filovirus haemorrhagic fever was available. ${ }^{17}$ In September 2014 WHO also issued a health and safety handbook for its deployed headquarters and country staff responders (clinical and non-clinical), which focused on personal measures staff could take to prevent exposure. ${ }^{18}$

Although WHO-convened teams had essential IPC training, in its report on health worker Ebola infections, WHO found '....serious gaps in IPC standards... in the settings where transmission likely took place or where infected health workers were employed. ${ }^{6}$ The report identified other risk factors for caregiver infections, grouped into several domains. These included deficiencies in administrative controls or work organisation, lack of engineering and environmental controls related to isolation and hygiene and problems with availability and compatibility of PPE. Also listed were poor employment conditions (human resource issues). ${ }^{6}$ Many of these domains are outside the confines of IPC but are addressed in MSF policies. They also mirror the classical occupational health exposure prevention approach of hazard anticipation, mitigation and control using engineering and administrative methods, work organisation and PPE. ${ }^{19} 20$

While compliance with safety policies was not formally tracked, the desired safety behaviours were routinely reinforced, as described above. We believe that organisational commitment and robust adherence to both IPC and other safety policies help explain MSF's lower staff infection rates and suggest a roadmap for future pandemic planning. Specifically, occupational health approaches to identify and control hazards, assure safe work organisation through assigned safety roles and responsibilities and vigilant PPE use augment and fortify standard IPC practices. Together, these efforts form a more protective, comprehensive safety programme, as the MSF outcome demonstrates.

\section{CONCLUSIONS}

As WHO has now declared the current Ebola outbreak in the Democratic Republic of Congo a "public health emergency of international concern', ${ }^{21}$ the global response must advance beyond efforts to raise staffing numbers and medical competency. Indeed, a competent response requires a protected health workforce. Building on the MSF experience, pandemic planning and emergency response starts with the comprehensive organisation of the care mission from a safety perspective. This requires anticipating hazards and providing linked prevention services, training commensurate to the significant hazards present and appropriate and sufficient protective equipment for caregivers. These duty of care actions form a fortified framework of safety and health protections for the health workforce, which in turn, add resilience to fragile health systems.

Acknowledgements The authors thanks Drs Axelle Ronsse and Rosemary Sokas and Ms Elyse DeLaittre for thoughtful review of the manuscript and Ms Marian Condon for skillful manuscript preparation.

Contributors MM and RC participated in the writing, reviewing and editing of the article.

Funding The authors have not declared a specific grant for this research from any funding agency in the public, commercial or not-for-profit sectors.

Competing interests None declared.

Patient consent for publication Not required.

Provenance and peer review Not commissioned; externally peer reviewed.

Data availability statement № additional data are available.

Open access This is an open access article distributed in accordance with the Creative Commons Attribution Non Commercial (CC BY-NC 4.0) license, which permits others to distribute, remix, adapt, build upon this work non-commercially, and license their derivative works on different terms, provided the original work is properly cited, appropriate credit is given, any changes made indicated, and the use is non-commercial. See: http://creativecommons.org/licenses/by-nc/4.0/.

\section{REFERENCES}

1. McDiarmid M. Advocating for the health worker. Ann Glob Health 2019;8510.5334/aogh.2461

2. Kruk ME, Myers M, Varpilah ST, et al. What is a resilient health system? Lessons from Ebola. Lancet 2015;385:1910-2.

3. $\mathrm{ICOH}$ occupational health for health workers. Available: http://www. icohweb.org/site/scientific-committee-detail.asp?sc=19 [Accessed 2 May 2019].

4. CDC/NIOSH: state of the sector: healthcare and social assistance, a NORA report, 2009. Available: https://www.cdc.gov/niosh/docs/ 2009-139/pdfs/2009-139.pdf [Accessed 6 Feb 2019].

5. Health and safety authority (HAS) healthcare illness and injury statistics, 2019. Available: https://www.hsa.ie/eng/Your_Industry/ Healthcare Sector/Healthcare injury and illness statistics.pdf

6. World Health Organization. Health worker Ebola infections in Guinea, Liberia and Sierra Leone: preliminary report, 2015. Available: https:// www.who.int/csr/resources/publications/ebola/health-workerinfections/en/ [Accessed 29 Nov 2018].

7. Vetter P, Dayer J-A, Schibler M, et al. The 2014-2015 Ebola outbreak in West Africa: hands on. Antimicrob Resist Infect Control 2016;5.

8. Duhaime's Law Dictionary. Duty of care definition. Available: http:// www.duhaime.org/LegalDictionary/D/DutyofCare.aspx [Accessed 26 Apr 2019]. 
9. Sokol DK. Virulent epidemics and scope of healthcare workers' duty of care. Emerg Infect Dis 2006;12:1238-41.

10. Goldkin D, Markwell $\mathrm{H}$. The duty to care of healthcare professionals: ethical issues and guidelines for policy development. Toronto: Joint Center for Bioethics, University of Toronto, 2003.

11. Health and Safety Executive, Duty of Care Employer's Responsibility. Available: http://www.hse.gov.uk/workers/employers.htm [Accessed 26 Apr 2019].

12. MSF. Duty of care project MSF internal document, general Directorate, Brussels, revised 2017.

13. MSF. Health guidelines and procedures for expatriate staff, MSF internal document 2012.

14. MSF. National staff health policies, MSF internal document 2010.

15. MSF. Ebola guideline, staff health chapter, MSF internal document draft 2017;3

16. WHO interim infection prevention and control guidance for care of patients with suspected or confirmed filovirus haemorrhagic fever in health-care settings, with focus on Ebola, 2014. Available: https:// apps.who.int/iris/bitstream/handle/10665/130596/WHO_HIS_SDS_ 2014.4_eng.pdf;sequence $=1$ [Accessed 27 Jun 2019].
17. WHO interim infection control recommendations for care of patients with suspected or confirmed filovirus (Ebola, Marburg) haemorrhagic fever, 2008. Available: http://ebolaalert.org/wpcontent/themes/ ebolaalert/assets/PDFS/SOPForInfectionControlForEVDCases.pdf [Accessed 27 Jun 2019].

18. WHO Ebola outbreak response Handbook for health and safety in the field, 2014 [Accessed 28 Jun 2019].

19. Weber A. Occupational hygiene: control of exposures through intervention. ILO encyclopedia of occupational health and safety, 2011. Available: http://www.iloencyclopaedia.org/part-iv-66769/ occupational-hygiene-47504 [Accessed 31 Jan 2019].

20. Occupational safety and health administration (OSHA). recommended practices for safety and health programs. hazard prevention and control. Available: https://www.osha.gov/ shpguidelines/hazard-prevention.html [Accessed 13 Dec 2018].

21. WHO: Ebola outbreak in the Democratic Republic of Congo declared a public health emergency of international concern. Available: https://www.who.int/news-room/detail/17-07-2019-ebola-outbreakin-the-democratic-republic-of-the-congo-declared-a-public-healthemergency-of-international-concern [Accessed 18 Jul 2019]. 